\title{
Recalculation of historical streamflow series. Impact assessment and valorization
}

\author{
Arnaud Belleville, ${ }^{1,}$, Alexandre Hauet ${ }^{1}$, Amélie Tacnet ${ }^{1}$ and Damien Sevrez ${ }^{1}$ \\ ${ }^{1}$ EDF - DTG, Water Resources Department, 38040 Grenoble Cedex 9, France
}

\begin{abstract}
Rating curves used to calculate discharge from water level must be extrapolated beyond the range of measured discharges, due to the difficulty of measuring flood discharge. This induces large uncertainties and the flood discharge series can be unreliable. This paper presents a methodology to update and correct historical flood flows, so as to propose homogeneous and less biased data. The benefit of using hydraulic modeling is discussed. This methodology is applied to a large sample of hydrometric stations of the EDF (Electricité De France) network, and the impact on peak flows deviations is analyzed.
\end{abstract}

\section{Introduction}

Hydrometric data are essential for many hydrological issues such as flood forecasting and warning, engineering design and policy decisions related to water resource management as well as calibration of hydrological models. EDF (Electricité De France) is the world's largest electricity producer, with an installed capacity of about $140 \mathrm{GWhe}$. In order to safely operate the power plants, to optimize the natural resources and to fulfill ecological requirement, EDFDTG has installed, since 1946, a sensor network dedicated to the monitoring of hydrometeorologic parameters, such as river discharge (about 300 hydrometric stations), rainfall and snowfall (water equivalent), air temperature and water quality.

Hydrometric stations do not measure directly river discharge. Streamflow time series are most often computed through use of a stage-discharge rating curve that relates measured river stage to streamflow discharge. The rating curve is a hydraulic model, which is usually developed using discrete measurements of stage and discharge (so called gaugings) as calibration data. The river bed can change over time and lead to non-stationary stagedischarge relationships depending on the geological nature of the catchment, on seasonal vegetation growth, or on hydro-meteorological events.

As illustrated on Figure 1, the hydrometric stations are mainly located on the French mountain ranges (Alps, Pyrenees and Massif Central), at high altitude, on small rivers with important slopes. The variability of the rating curves, which reflects the stability of hydraulic controls, differs from one massif to another. This variability is expressed from the lifetime of the rating curves. The shorter the lifetime, the less stable the hydraulic control. Thus, in the Alps, where the erosion and sedimentation processes are more significant, the frequency of updating the curves is higher than in other massifs.

\footnotetext{
* Corresponding author: arnaud.belleville@edf.fr
} 


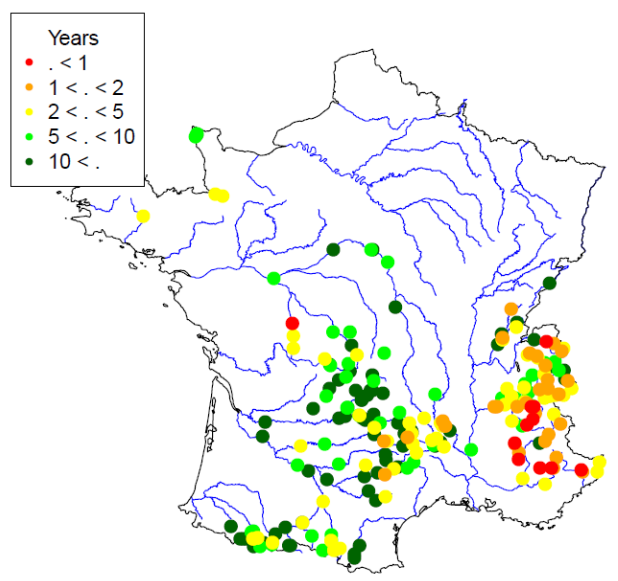

Fig. 1. Rating curves lifetime on EDF hydrometric network. Period 2007-2017

Moreover, gaugings flood discharge can be very tricky, especially for mountainous river [1]. As a consequence, the rating curves must be extrapolated for high flows, which brings a lot of uncertainties. The flood discharge series can be unreliable, impacting significantly flood forecasting, the sizing of structure like dam spillway, and so people's safety [2].

After a state of the art of extrapolation practices of the rating curves (section 2), the contribution of topographic data and hydraulic modeling for the extrapolation of the rating curve is detailed (section 3). Finally, we present a methodology for recalculating peak flow series, so as to propose homogeneous and less biased flood data (section 4). This methodology is applied to a large sample of hydrometric data, followed by an impact assessment on flood data.

The French hydrometric station of Trebons-Bas located on the Vioulou River (watershed $57 \mathrm{~km}^{2}$, in the south-west of France) will be used as an example throughout the paper. This station measures the natural Vioulou flow entering the reservoir of Pareloup. The hydraulic control of this hydrometric station is a section control.

\section{Extrapolation of rating curves - State of the art}

During flood, it is frequently impossible or impractical to measure the peak discharges when they occur, because of the following conditions:

(a) Roads may be impassable ;

(b) Knowledge of the flood rise may not be available sufficiently in advance to permit reaching the site near the time of the peak ;

(c) The flood peak may be so sharp that a satisfactory direct discharge measurement could not be made even if a field hydrologist is present at the time ;

(d) The flow of debris may be such as to prevent use of sounding equipment;

(e) And staff safety must be preserved before anything else.

Thus, rating curves must be extrapolated beyond the range of measured discharges. A study carried out on 325 hydrometric stations in France (mainly located on the Rhone watershed) studied the period of return of the maximum value of gauged discharge [3]. For most of stations, the maximum flow has a period of return of less than 2 years. Very few stations (less than 10\%) are gauged beyond the 10-year flood.

Several methods exists to extrapolate rating curves for high flow [4]. A strong assumption is made for the extrapolation: the existence of a stable stage-discharge relationship beyond a certain discharge value. The idea underlying this assumption is that the rating curve 
converges for high flow independently of its variability for low flows. This assumption is correct in the majority of cases because the global geometry of a channel does not change in time, with the exception of very particular cases of complete rehabilitation of the flow channel.

Extrapolation methods implemented at EDF are based on two complementary approaches. The first approach focuses on hydrological considerations, such as spatial comparison of peak runoff rates. When flood stages are produced over a large area by an intense general storm, the peak discharges can often be estimated at gauging stations where they are lacking from the known peak discharges at surrounding stations. Usually each known peak discharge is converted to peak discharge per unit of drainage area. If there has been relatively little difference in storm intensity over the area affected, peak discharge per unit area may be correlated with drainage area. The peak discharge estimated by this method can be used as a guide in extrapolating the rating curve at a gauging station.

The second approach is based on hydraulic considerations. Different hydraulic models can be implanted, from the simplest (double log plot method, relation between average velocity and stage) to the most evolved (1D or $2 \mathrm{D}$ numerical model). The latter has recently been massively deployed on the EDF hydrometric network (see section 3).

By examining historical rating curves of some hydrometric stations, heterogeneity is often observed in the extrapolations for high flow, as illustrated on Fig.2. This heterogeneity contradicts the assumption of the convergence of the stage-discharge relationship for high flow. This can be explained by the input of new informations over time, like flood gauging, topographic survey, hydraulic modeling, that have not necessarily been valuated over the past period.

With the aim of producing homogeneous and less biased streamflow series, a work of reanalysis has been started, by using hydraulic modeling.
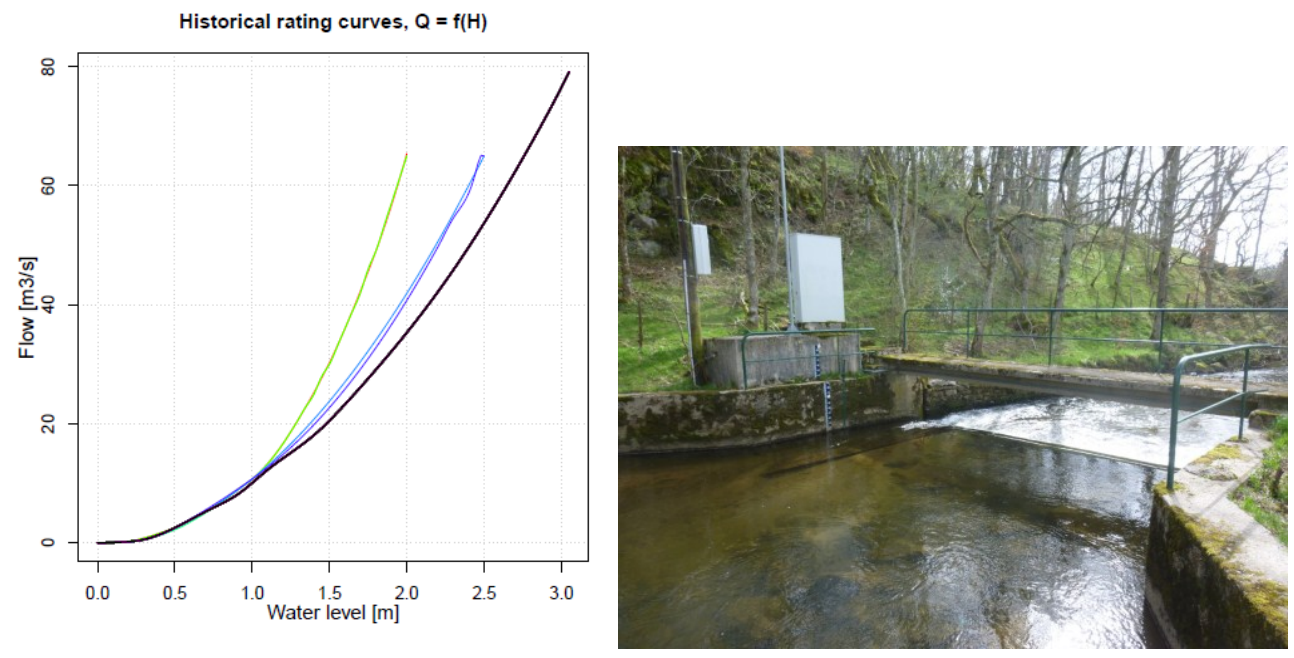

Fig. 2. Different extrapolations of historical rating curves - Hydrometric station of Trebons-Bas (in black: current rating curve) and a picture of the station of Trebons-Bas showing the weir controlling the flow. 


\section{Hydraulic modeling for extrapolating rating curves}

For 170 of its hydrometric stations (more than a half of the hydrometric network), EDF DTG has realized topographic surveys and 1D hydraulic models during a 3 years project. The model is used for high flow conditions, to understand the hydraulics of flood.

\subsection{Implementation of the hydraulic model}

For each studied station, preliminary researches are conducted to get hydrologic, topographic and hydraulic informations. Pictures of the site, previous hydraulic studies, river slopes, geologic maps, land use maps, etc... are collected. Then, a site visit is realized by the modeler and the topographer in order to define precisely the location of the transects to be included in the model. Special attention is given to the identification of downstream conditions that may act as hydraulic control during flood, like bridges, dam, or important overflow plain. An evaluation of the Strickler coefficient Ks for the river and flood plain is made.

The second step consists in the topographic survey, including bathymetry of the river and topography of the flood plains. Last, the hydraulic model is built using the 1D code Mascaret [5]. The calibration of the model is realized with the Ks, using the existing gaugings as reference.

\subsection{Results of the model}

The topographic data are used in the model, and are also stored in GIS database. 20 equidistant flow rates between 0 and the 100-year flood are modeled, and the corresponding stage at the hydrometric station is computed. The modeled rating curve is reviewed and criticized by the field hydrologist in charge of the hydrometric station. The stage above which a stable rating curve is expected is defined, and this part of the rating curve is included in the tracing of the operational rating curve.

Figure 3 shows the rating curve used at Trebons-Bas before the model, and the modeled rating curve. The gaugings were all realized for medium flow condition and are not representative of the high flows. The model shows that the impact of the weir being submerged and the impact of the bridge overestimate the stage for a given discharge (see Figure 3).

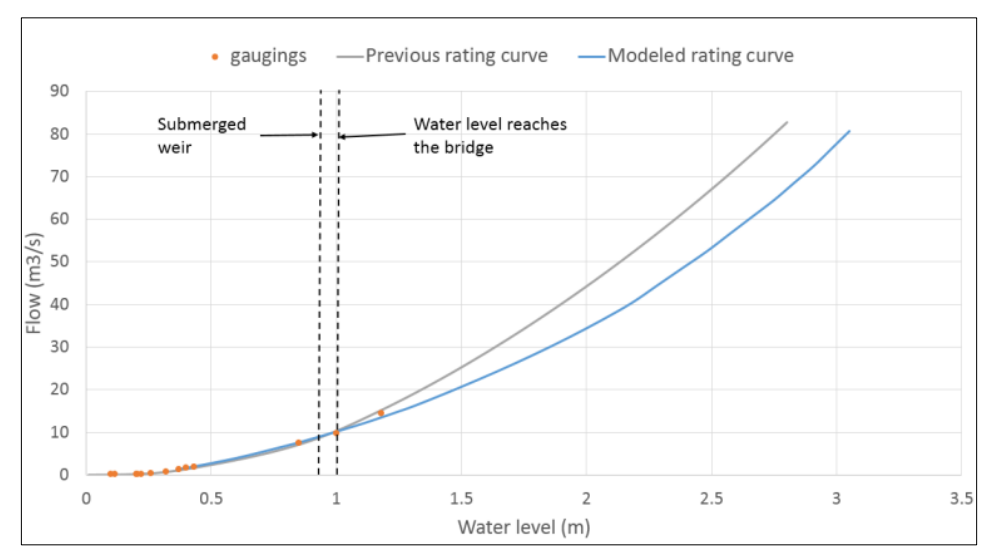

Fig. 3. Modeled rating curve vs previous rating curve at Trebons Bas

Even if modeling is not perfect representation of reality, it values all the available information at a hydrometric station (slope, roughness, topography, downstream control, hydraulic). 


\section{Recalculation of historical peak flows}

\subsection{Methodology}

Recalculation of peak flows is made from the water level series available in the database. These data are generally present from the early of 80 's, corresponding to the beginning of the remote data transmission. The homogeneity of the water level series is analyzed in order to detect breaks in the mode of production of the series: staff gauge moving, drastic change of the hydraulic control... A homogeneous period is then identified to carry out the recalculation.

The floods are sampled from the water level series, at the rate of 2 floods per year on average. The selection is made from the water level series, and not from the discharge series, because of the heterogeneity of the flow series induced by the heterogeneity of the extrapolation of the rating curves. The range of the levels in which the floods are selected must be in the convergence zone of the stage-discharge relationship.

Peak flows are finally recalculated using two rating curves and then compared to the historical peak flows stored in the database:

- The rating curve used currently by the field hydrologist. This rating curve valorizes the maximum of available hydrometric information and the most complete expertise from the field hydrologist. The recalculated peak flows are called homogenized peak flows.

- The rating curve resulting from the hydraulic modeling. The recalculated peak flows are called modeled peak flows.

\subsection{Results}

\subsubsection{Illustration on the hydrometric station of Trebons-Bas}

Water level series are available since 1983. No major changes have been identified in the hydraulic control or in the datum of the staff gauge over the period. The full period is kept, and 70 floods are selected. Figure 4 shows the four major floods, with the 3 discharge hydrographs (historical, homogenized and modeled), and the relation between modeled and historical peak flows.

Deviations between recalculated peak flows and historical peak flows are calculated for each flood, and represented as a boxplot (see Figure 5). In the case of Trebons-Bas, the valorization of the hydraulic modeling generally leads to a downward revision of the values of peak flows. 

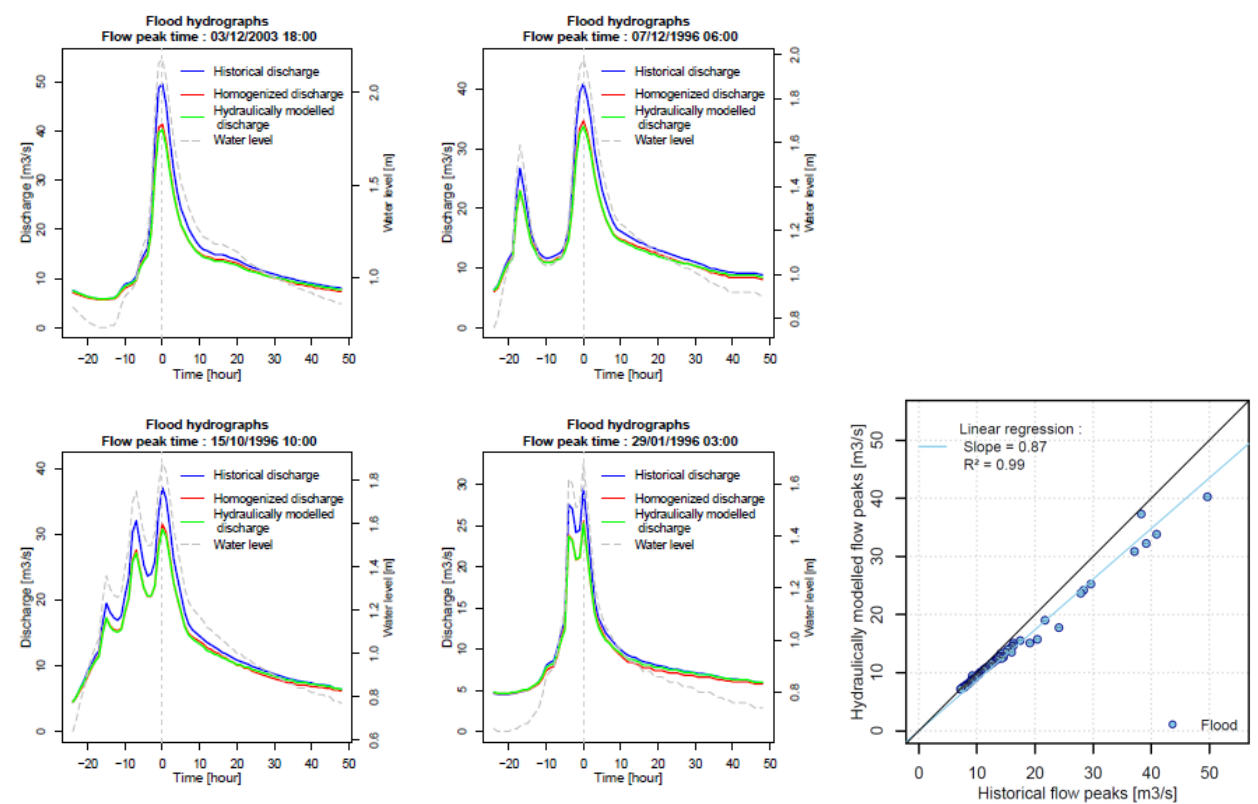

Fig. 4. Left: example of flood hydrographs of Trebons-Bas station with the three streamflow series (historical, homogenized and hydraulic modeling) - Right: relation between modeled peak flows and historical peak flows for the selected floods sample
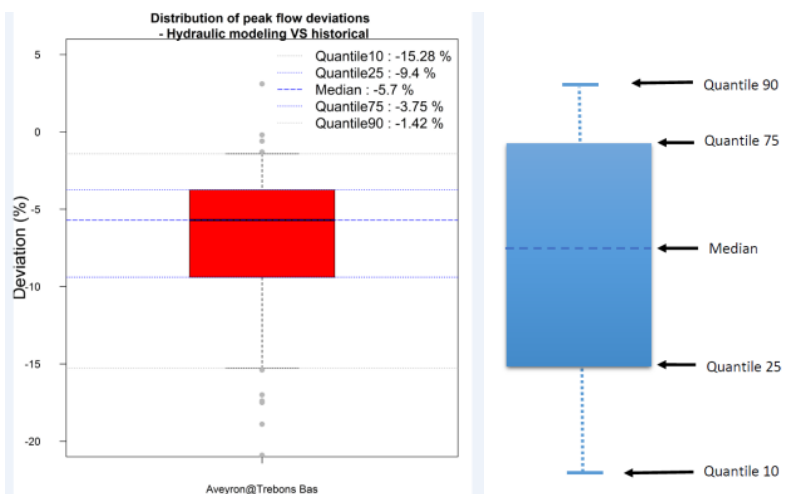

Fig.5. Distribution of peak flow deviations between modeled and historical discharges. Left: results on Trebons-Bas - Right: boxplot value description.

\subsubsection{Results on a sample of hydrometric stations}

The analysis is extend to a representative panel of hydrometric stations of EDF-DTG network, for which we have a validated hydraulic modeling study. 85 stations are selected and well spatially distributed, as shown Figure 8.

Figure 6 represents the distribution of the boxplots of deviations between modeled and historical peak flows. We note that global bias is very limited, with a mean value of $-2.2 \%$ (hydraulic modeling leads to a slight decrease of peak flows). The median deviation is less than $10 \%$ (which can be considered as the reasonable uncertainty for flood flows) in $70 \%$ of the cases, but the deviation and the variance may be considerable for some stations, reaching $60 \%$. 
The distribution is globally symmetrical with respect to the upward or downward reevaluation of peak flows. Figure 7 represents a histogram of deviations of peak flows computed on the 4074 floods sampled on the 85 hydrometric stations. We can note that the predominant deviations are due to the homogenization. The hydraulic modeling produced both overestimations (more discharge for the same water stage) and underestimations (less discharge for the same water stage) of the rating curves. Overestimations are mainly due to overflows on floodplain, increasing the wetted areas. Underestimations are mainly due to the activation of downstream hydraulic controls for high flows, like bridges or dams.

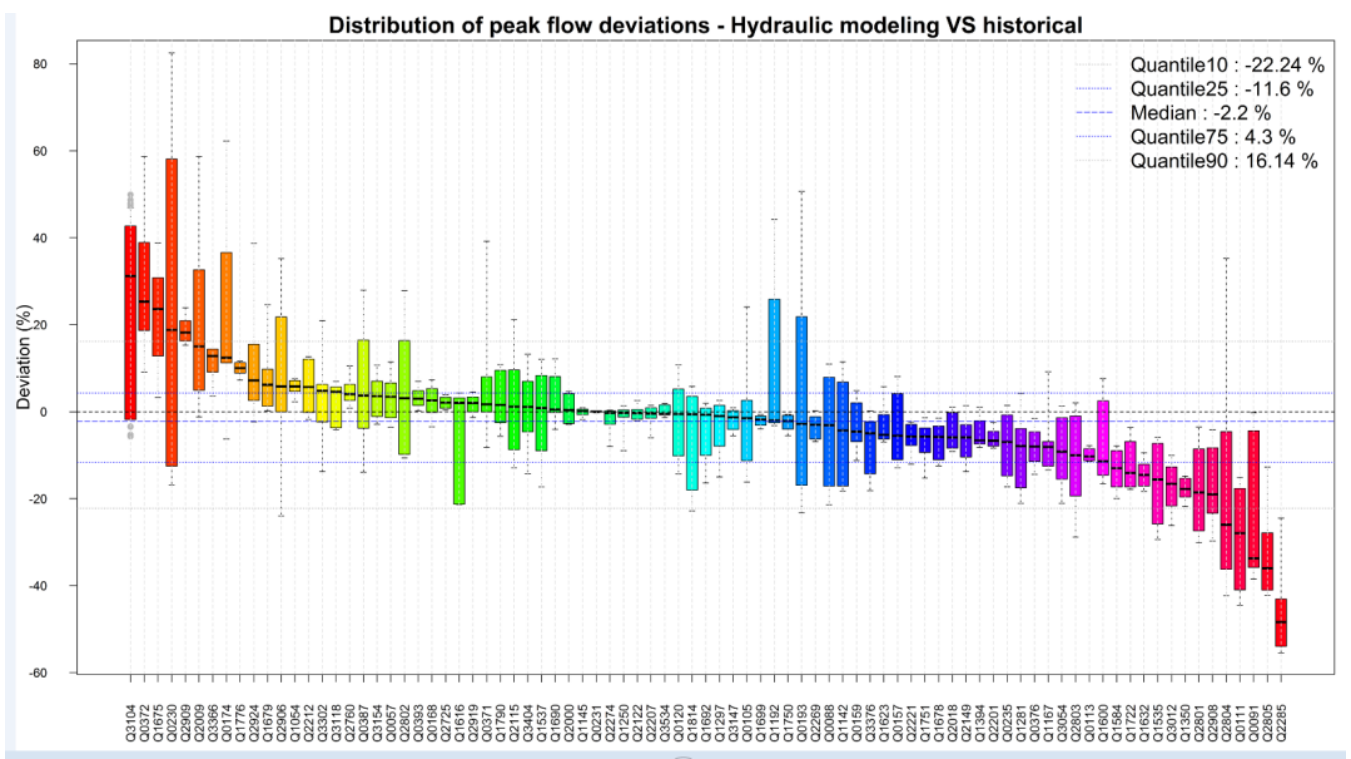

Fig. 6. Distribution of deviations between modeled and historical peak flows.

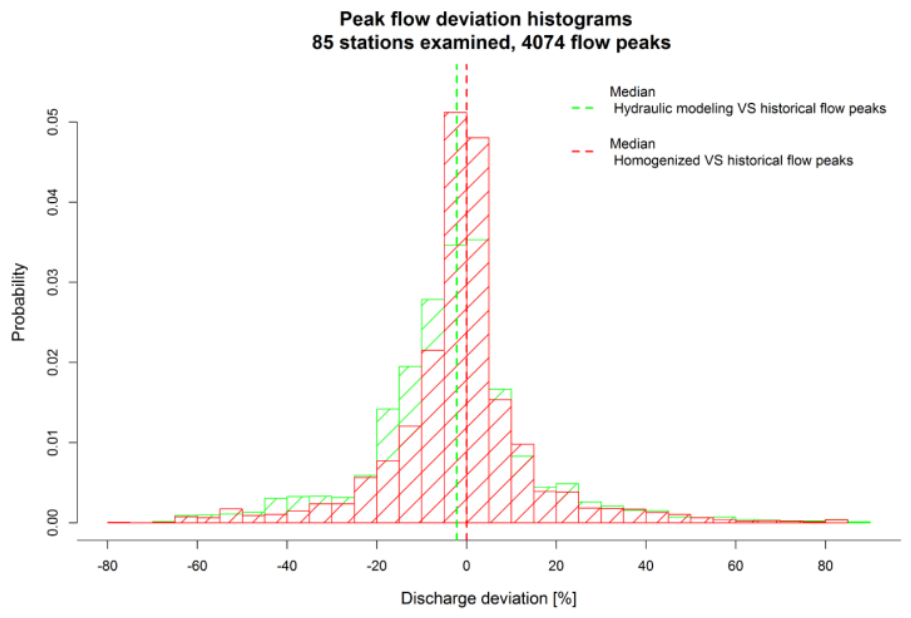

Fig. 7. Peak flow deviation histograms for the two approaches: homogenization and hydraulic modeling.

Figure 8 shows the spatial distribution of median deviations between modeled and historical peak flows. No regional trend can be particularly highlighted. Each analysis depends on local conditions, related to the specificity of the hydraulic control, and to the management of the rating curve. 


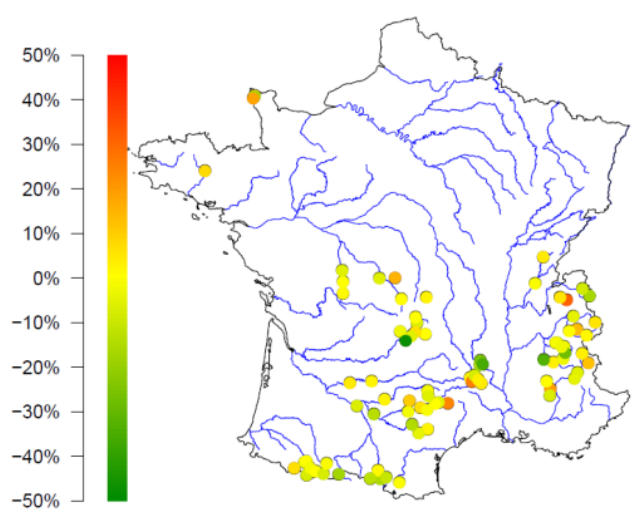

Fig. 8. Spatial distribution of median deviations between modeled and historical peak flows.

\section{Conclusions and perspectives}

Factors that could lead to heterogeneity or bias in flow series, especially for high flows, have been highlighted. Critical analysis of extrapolations of rating curves, particularly with the help of hydraulic modeling, improves data quality.

The study presented in this paper allows compiling a catalog allowing to identify the stations which require a revision of the historical streamflow series. A complete reanalysis of the data can then be conducted on these stations in a rigorous way, by implementing for example a dynamic rating curve method [6]. This method allows to produce homogeneous data over the whole range of observed flows that can be directly valued in extreme flood estimation studies [7].

This analysis will be extended to 170 hydrometric stations once all hydraulic modeling studies have been validated.

\section{References}

1. S. Rantz, Measurement and computation of streamflow, Tech.Rep., U.S. Geological Survey Water-Supply Paper, 2175, vol.2 (1982)

2. M. Lang, K. Pobanz, B. Renard, E. Renouf, E. Sauquet Extrapolation of rating curves by hydraulic modeling with application to flood frequency analysis, Hydrological Sciences Journal, 55(6) :883-889 (2010)

3. M. Lang, C. Perret, E. Renouf, E. Sauquet, A. Paquier, Incertitudes sur les débits de crue (Uncertainty of flood discharge estimates), La Houille Blanche, $\mathbf{n}^{\circ} \mathbf{6}, 33-41$ (2006)

4. WMO, Manual on stream gauging - Vol II - Computation of discharge, WMO $\mathbf{n}^{\circ} \mathbf{1 0 4 4}$ (2010)

5. N. Goutal and F. Maurel, A Finite Volume Solver for 1D Shallow-Water Equations Applied to an Actual River, Int. J. Numer. Meth. Fluids, 38:1-19 (2002)

6. T.Morlot, C. Perret, A.-C Favre, J. Jalbert, Dynamic rating curve assesment for hydrometric stations and computation of the associated uncertainties: Quality and station management indicators, Journal of Hydrology, Volume 517, 173-186 (2014)

7. E.Paquet, F.Garavaglia, R.Garçon, J.Gailhard, The SCHADEX method: a semicontinuous rainfall-runoff simulation for extreme flood estimation, Journal of Hydrology, Volume 495, 23-37 (2013) 